\title{
Sistema radicular do Panicum maximum Jacq. cv. IPR-86 Milênio adubado com nitrogênio e submetido à lotação rotacionada ${ }^{1}$
}

\section{Patrícia Sarmento ${ }^{2}$, Luís Roberto de Andrade Rodrigues ${ }^{3}$, Simony Marta Bernardo Lugão ${ }^{4}$ Mara Cristina Pessôa da $\mathrm{Cruz}^{3}$, Fábio Prudêncio de Campos ${ }^{5}$, Manoel Evaristo Ferreira ${ }^{3}$, Ricardo Ferraz de Oliveira ${ }^{6}$}

\author{
1 Projeto financiado pelo IAPAR e apoiado pela UNESP/FCAV. \\ 2 Programa de Pós-graduação em Zootecnia - UNESP. \\ 3 UNESP/FCAV - Via de Acesso Prof. Paulo Donato Castellane, s/n, CEP: 14884-900, Jaboticabal - SP. \\ ${ }^{4}$ IAPAR - CP 564, CEP: 87701-970, Paranavaí - PR. \\ ${ }^{5}$ Programa de Pós-Doutoramento - Depto. de Zootecnia - USP/ESALQ. \\ ${ }^{6}$ USP/ESALQ - Av. Pádua Dias, 11, CP 9, CEP: 13418-9000, Piracicaba - SP.
}

RESUMO - Avaliou-se o efeito do nitrogênio no sistema radicular da espécie Panicum maximum Jacq. cv. IPR-86 Milênio, sob pastejo. As doses de N utilizadas foram 0; 150; 300 e 450 kg/ha.ano. As densidades de raízes no pré-pastejo foram avaliadas no quinto ano de aplicação de $\mathrm{N}$, em três profundidades (0-10;10-20 e 20-40 cm), com crescimento aos 7; 14; 21 e 35 dias após o pastejo. O método de pastejo utilizado foi o de lotação rotacionada. Os valores máximos de densidades de comprimento e de massa das raízes no pré e no pós-pastejo foram obtidos nas doses de N de 204; $206 ; 192$ e 197 kg/ha, respectivamente. Nas doses de $\mathrm{N}$ de 0,150 e $300 \mathrm{~kg} / \mathrm{ha}$, o crescimento das raízes (em densidade de comprimento) aumentou, em média, até 29 dias após o pastejo, enquanto, na dose $450 \mathrm{~kg} / \mathrm{ha}$, o aumento foi linear. Independentemente da dose de $\mathrm{N}$, 60 a 25\% do sistema radicular do cultivar IPR-86 Milênio concentrou-se nas camadas de 0-10 e 10-20 cm de profundidade, respectivamente.

Palavras-chave: densidade de raiz, gramínea, pastagem

\section{Root system of Panicum maximum Jacq. cv. IPR-86 Milênio fertilized with nitrogen and submitted to rotational stocking}

\begin{abstract}
The effect of nitrogen on the root system of the species Panicum maximum Jacq. cv. IPR-86 Milênio, under grazing, was evaluated. The $\mathrm{N}$ rates were $0 ; 150 ; 300$ and $450 \mathrm{~kg} / \mathrm{ha}$.year. The root density was evaluated during pregrazing at five years of successive $\mathrm{N}$ application, in three depths $(0-10 ; 10-20$ and $20-40 \mathrm{~cm})$ and the root growth at 7,14 21, and 35 days after grazing. The grazing method adopted was rotational stocking. Root length and root mass densities in pre- and post- grazing presented maximum values at rates 204, 206, 192, and $197 \mathrm{~kg} / \mathrm{ha}$ of $\mathrm{N}$, respectively. The root growth (in root length density) increased, on average, until 29 days after grazing at rates 0,150 , and $300 \mathrm{~kg} / \mathrm{ha}$; at $450 \mathrm{~kg} / \mathrm{ha} \mathrm{N} \mathrm{rate,}$ the increase was linear. Independently of $\mathrm{N}$ rates, around 60 and 25\% of IPR-86 Milênio cultivar root system was concentrated in 0-10 and 10-20 cm depth, respectively.
\end{abstract}

Key Words: grass, pasture, root density

\section{Introdução}

Na maioria das pesquisas com pastagens, o estudo do crescimento e do desenvolvimento da parte aérea das plantas é priorizado em detrimento à sua interdependência com as raízes e à influência dos atributos físicos e químicos do solo, do clima e do manejo da planta forrageira sobre essas variáveis. O nitrogênio, entre os nutrientes, é o principal responsável pelo aumento da produção de forragem e da lotação das pastagens, principalmente nas espécies com elevado potencial produtivo. No entanto, quando as gramíneas são submetidas ao pastejo, normalmente apenas a parte aérea das plantas é avaliada.

O fornecimento de nutrientes afeta o crescimento das raízes e sua morfologia e a densidade das raízes aumenta rapidamente nos locais de maior concentração do fertilizante (Marschner, 1995). O pequeno volume e a má distribuição do sistema radicular ao longo do perfil do solo tornam a planta mais susceptível a déficits hídricos, prejudicando sua sustentação e restringindo a exploração de

Este artigo foi recebido em 10/8/2006 e aprovado em 17/7/2007. 
nutrientes a um pequeno volume de solo (Marschner, 1995; Singh, 1999).

Aumento na taxa de lotação das pastagens promove maior pressão no solo pelas patas dos animais e resulta em compactação do solo, que prejudica o desenvolvimento radicular e diminui a produção de forragem (Greenwood \& Mckenzie, 2001). No entanto, o sistema radicular limita a compactação, pois forma macroporos e aumenta a quantidade de matéria orgânica do solo, o que auxilia na estabilização da estrutura do solo (Greenwood \& Mckenzie, 2001).

$\mathrm{O}$ crescimento, a distribuição e a morte das raízes da planta forrageira também são influenciados pela desfolha, que, por sua vez, promove redução na massa seca de raízes após o pastejo geralmente proporcional à intensidade e à freqüência de desfolha (Corsi et al., 2001; Donaghy \& Fulkerson, 2002).

Logo após o pastejo, parte das raízes das plantas morre em decorrência da desfolhação. O crescimento radicular durante a rebrotação do capim é importante para a descompactação do solo. Além disso, a absorção de nutrientes e de água pela planta para a retomada do crescimento da parte aérea após o pastejo depende do suporte radicular da gramínea.

$\mathrm{O}$ estudo do crescimento do sistema radicular de gramíneas e dos fatores que o influenciam é fundamental para definir critérios que auxiliem nas práticas de manejo e que assegurem a persistência da pastagem. Assim, realizou-se este trabalho para avaliar o efeito da adubação nitrogenada no sistema radicular do Panicum maximum Jacq. cv. IPR-86 Milênio sob pastejo.

\section{Material e Métodos}

O experimento foi conduzido no Instituto Agronômico do Paraná (IAPAR), 2300'4" S, 42002'06" W e altitude de
480 m, em Paranavaí, PR. O experimento foi estabelecido em Argissolo Vermelho Amarelo distrófico, textura arenosa, com areias $(890 \mathrm{~g} / \mathrm{kg})$, argila $(100 \mathrm{~g} / \mathrm{kg})$ e silte $(10 \mathrm{~g} / \mathrm{kg})$. A análise química do solo (Tabela 1) foi obtida segundo os métodos descritos por Van Raij et al. (1987). O clima predominante da região é o Cfa subtropical úmido mesotérmico, segundo classificação de Köeppen. Os dados de precipitação pluvial e de temperatura média registrados na Estação Agroclimática do IAPAR-Paranavaí foram 241; 328; 99 e $79 \mathrm{~mm}$ e 24,$1 ; 24,6 ; 26,0$ e $25,5^{\circ} \mathrm{C}$, em quatro ciclos de pastejo: de 29/11/2001 a 8/1/2002; de 8/1/2002 a 17/2/2002; 17/2/2002 a 29/3/2002; e de 29/3/2002 a 8/5/2002, respectivamente.

O Panicum maximum Jacq. cv. IPR-86 Milênio foi semeado em 1995 e as doses de N $(0 ; 150 ; 300$ e 450 kg/ha) foram aplicadas, ano a ano, desde 1997. As avaliações cujos resultados são apresentados neste trabalho referem-se ao período de outubro de 2001 a maio de 2002.

As doses 0 e $150 \mathrm{~kg} / \mathrm{ha}$ foram aplicadas em unidades experimentais com área de $1.687,5 \mathrm{~m}^{2}$ cada uma $(36 \mathrm{~m} \times$ $46,87 \mathrm{~m}$ ) e as doses 300 e $450 \mathrm{~kg} / \mathrm{ha}$ em áreas com 837,5 m² cada uma $(36 \mathrm{~m} \times 23,3 \mathrm{~m})$. A aplicação de nitrogênio na forma de nitrato de amônio $(150 ; 300$ e $450 \mathrm{~kg} / \mathrm{ha})$ foi parcelada em três doses iguais durante o período chuvoso (outubro/ novembro de 2001; dezembro/janeiro de 2001/2002 e janeiro/ fevereiro de 2002) e distribuída a lanço um dia após a saída dos animais dos piquetes.

Não foi aplicado calcário no ano de 2001, uma vez que os valores de saturação por bases do solo em junho desse ano eram 68; 65; 67 e 65\% na camada de 0 a $20 \mathrm{~cm}$ de profundidade nas parcelas adubadas com nitrogênio nas doses de $0 ; 150 ; 300$ e $450 \mathrm{~kg} / \mathrm{ha}$, respectivamente. Nessa mesma época de amostragem, os teores de $\mathrm{P}$ e K no solo na profundidade de 0 a $20 \mathrm{~cm}$ foram 7; 7; 7 e $9 \mathrm{mg} / \mathrm{dm}^{3}$ (Mehlich-1) e 2,$7 ; 2,1 ; 3,5$ e $2,9 \mathrm{mmol}_{\mathrm{c}} / \mathrm{dm}^{3}$, respectivamente, nos piquetes

Tabela 1 - Atributos químicos ${ }^{1}$ do solo das pastagens de capim-milênio no início do período experimental, em outubro de 2001

\begin{tabular}{|c|c|c|c|c|c|c|c|c|c|c|c|}
\hline Dose de $\mathrm{N}$ & Profundidade & $\mathrm{P}^{2}$ & MO & $\mathrm{pH}$ & $\mathrm{H}+\mathrm{Al}$ & $\mathrm{Ca}$ & $\mathrm{Mg}$ & $\mathrm{K}$ & $\mathrm{SB}^{3}$ & $\mathrm{CTC}^{4}$ & \multirow{2}{*}{$\begin{array}{l}\mathrm{V}^{5} \\
\%\end{array}$} \\
\hline $\mathrm{kg} / \mathrm{ha}$ & $\mathrm{cm}$ & $\mathrm{mg} / \mathrm{dm}$ & $\mathrm{g} / \mathrm{dm}$ & $\mathrm{CaCl}_{2}$ & 一 & - & - & $/ \mathrm{dm}^{3}$ & & & \\
\hline 0 & $0-10$ & 17 & 15 & 6,1 & 11 & 22 & 11 & 2,0 & 35 & 46 & 76 \\
\hline 0 & $10-20$ & 5 & 12 & 5,7 & 13 & 13 & 6 & 1,8 & 21 & 34 & 62 \\
\hline 0 & $20-40$ & 3 & 8 & 5,2 & 15 & 10 & 6 & 1,5 & 18 & 33 & 53 \\
\hline 150 & $0-10$ & 15 & 17 & 6,2 & 11 & 21 & 13 & 2,4 & 37 & 48 & 77 \\
\hline 150 & $10-20$ & 4 & 12 & 5,5 & 13 & 14 & 7 & 1,9 & 23 & 36 & 63 \\
\hline 150 & $20-40$ & 3 & 8 & 4,9 & 18 & 9 & 6 & 1,4 & 16 & 34 & 47 \\
\hline 300 & 0-10 & 16 & 21 & 6,1 & 13 & 23 & 17 & 3,7 & 44 & 56 & 77 \\
\hline 300 & $10-20$ & 6 & 14 & 5,2 & 16 & 14 & 7 & 3,1 & 24 & 40 & 60 \\
\hline 300 & $20-40$ & 3 & 9 & 4,8 & 19 & 10 & 6 & 1,6 & 18 & 37 & 48 \\
\hline 450 & 0-10 & 15 & 20 & 6,0 & 13 & 22 & 15 & 3,9 & 41 & 54 & 76 \\
\hline 450 & $10-20$ & 6 & 14 & 5,1 & 18 & 12 & 8 & 2,9 & 22 & 39 & 56 \\
\hline 450 & $20-40$ & 4 & 10 & 4,7 & 19 & 10 & 6 & 1,9 & 18 & 37 & 49 \\
\hline
\end{tabular}

${ }^{1}$ Foram coletadas 25 subamostras por piquete para compor uma amostra; ${ }^{2}$ Extraído por resina; ${ }^{3}$ Soma de bases; ${ }^{4}$ Capacidade de troca de cátions:

5 Porcentagem de saturação por bases. 
adubados com nitrogênio $(0 ; 150 ; 300$ e $450 \mathrm{~kg} / \mathrm{ha})$ e, por isso, a adubação com $\mathrm{P}$ e $\mathrm{K}$ também não foi feita.

O método de pastejo utilizado foi o de lotação rotacionada, com cinco dias de ocupação e 35 dias de descanso. Utilizou-se a técnica put-and-take para ajustar o número de animais à oferta de forragem disponível. Consideraram-se o consumo de $70 \%$ de MS de lâminas verdes em relação à produção de forragem para cada do se de $\mathrm{N}$ e a oferta diária de lâminas verdes de $11 \mathrm{~kg}$ por $450 \mathrm{~kg}$ de peso corporal. Com o ajuste da lotação animal, pretendeu-se deixar a forragem residual equivalente a 20-25\% da MS de lâminas verdes em relação à produção para cada dose de N. Os animais utilizados foram machos mestiços não-castrados (Nelore $\times$ Marchigiana, Nelore $\times$ Simental e Nelore $\times$ Red Angus).

Realizou-se um estudo preliminar para definir o local de amostragem das raízes. Assim, tomaram-se quatro amostras eqüidistantes, entre a base da touceira até a projeção da copa da gramínea, para cada dose de $\mathrm{N}$ aplicada. Utilizou-se um trado cilíndrico com $7 \mathrm{~cm}$ de diâmetro e $10 \mathrm{~cm}$ de altura para coleta de raízes. O trado apresentava dentes em sua extremidade inferior que facilitaram o corte das raízes e a retirada das amostras sem perda do material. Posteriormente, as raízes foram lavadas, secas em estufa a $60-65^{\circ} \mathrm{C}$ por 72 horas e pesadas para determinação do teor de MS.

Com os resultados efetuou-se análise de regressão polinomial para a obtenção das distâncias entre a base da touceira até a projeção da copa, que apresentavam a quantidade mínima de MS de raízes por $\mathrm{cm}^{3}$ (24,25; 44,75; 40,17 e 43,88 cm, nas parcelas que receberam as doses $0 ; 150 ; 300$ e $450 \mathrm{~kg} \mathrm{ha}^{-1}$ de N, respectivamente). Para a dose testemunha, adotou-se a distância de $10 \mathrm{~cm}$ da base da touceira para a amostragem de raízes por ser o local onde havia raízes mais finas, responsáveis pela renovação do sistema radicular por serem mais susceptíveis à morte após o pastejo e por não haver raízes de plantas adjacentes.

A partir da medida de $10 \mathrm{~cm}$ utilizada na dose testemunha, efetuaram-se os ajustes correspondentes para as doses $150 ; 300$ e $450 \mathrm{~kg} /$ ha para obtenção das distâncias ajustadas de 18,45; 16,56 e 18,09 cm (média de 17,7 cm) da base da touceira, respectivamente. Em função disso, as amostras para avaliação do comprimento e da massa radicular foram retiradas a $18 \mathrm{~cm}$ de distância da base da touceira nas doses de $150 ; 300$ e $450 \mathrm{~kg} / \mathrm{ha}$.

Antes da entrada dos animais, foram coletadas seis amostras de raízes de três touceiras por piquete para avaliação da densidade de comprimento e de massa seca das raízes em três profundidades de solo (0-10,10-20 e 20-40 cm) e em três ciclos de pastejo (CP1; CP2 e CP4). As touceiras representativas da área foram escolhidas considerando a distância da base até a projeção da copa e marcadas em um mapa. Na coleta das raízes da gramínea durante os CP2 e $\mathrm{CP} 4$, foram escolhidas as mesmas touceiras avaliadas no $\mathrm{CP} 1$. As raízes foram lavadas com água corrente sobre duas peneiras superpostas com malha de $0,5 \mathrm{~cm}$. A seguir, cada amostra de raízes foi colocada em frasco com solução aquosa de álcool etílico comercial $300 \mathrm{~mL} / \mathrm{L}$ e armazenada em geladeira.

Para avaliação do crescimento radicular pós-pastejo, foram selecionadas seis touceiras representativas do piquete, em razão de seu comprimento e de sua largura, para confecção de covas cilíndricas no solo $(7 \times 10 \mathrm{~cm})$ próximas da base da touceira. As covas foram preenchidas com areia e amostradas, com auxílio do trado, 7, 14, 21 e 35 dias após o pastejo (seis repetições por piquete), entre 17/12/2001 e 11/2/2002. Na lavagem das raízes crescidas em areia, foram utilizadas duas peneiras superpostas com malhas de $0,2 \mathrm{e}$ $0,5 \mathrm{~cm}$. O modo de armazenagem das raízes foi o mesmo adotado para as amostras coletadas no pré-pastejo.

As raízes mortas foram separadas das amostras por meio de avaliação visual, conforme descrito por Tennant (1975).

As leituras do comprimento radicular foram realizadas por meio do aparelho DELTA T SCAN equipado com o programa de análise de imagem de raízes. Posteriormente, as raízes foram secas em estufa a $60-65^{\circ} \mathrm{C}$ por 72 horas e pesadas para determinação da MS. A massa de forragem no pré-pastejo foi obtida por meio do lançamento, ao acaso, de um quadrado de $1 \mathrm{~m}$ de lado. Foram colhidas três amostras por piquete, a $20 \mathrm{~cm}$ do solo, com uma tesoura de poda. As avaliações foram feitas em três ciclos de pastejo (CP1; CP2 e CP4). As amostras foram pesadas separadamente no campo e desse material foram retiradas três subamostras para separação em lâminas verdes, colmos + bainhas e material senescente + material morto. Outras três subamostras foram retiradas para determinação do teor de MS. Posteriormente, essas subamostras foram secas em estufa com ventilação forçada a $60-65^{\circ} \mathrm{C}$ por 72 horas.Os resultados de MS de lâminas no pré-pastejo foram utilizados para determinar a dose de $\mathrm{N}$ recomendada, considerando-se simultaneamente as respostas da parte aérea e do sistema radicular da gramínea.

O delineamento estatístico utilizado foi o inteiramente casualizado, em esquema de parcelas subdivididas, com medidas repetidas no tempo para o crescimento de raízes após o pastejo, com quatro repetições. Para a densidade de comprimento e de MS das raízes no pré-pastejo, o delineamento adotado foi o de parcelas subsubdivididas, com medidas repetidas no tempo e no espaço. As doses de $\mathrm{N}$ foram estudadas nas parcelas principais, os ciclos de pastejo 
e as idades de crescimento das raízes nas subparcelas e as profundidades de amostragem nas subsubparcelas.

A análise estatística dos resultados foi feita utilizando-se o procedimento MIXED do programa SAS (Statistical Analysis System), versão 8.2 para Windows (SAS, 1999). Para efeito de comparação das médias entre as profundidades e os ciclos de pastejo, utilizou-se o teste Tukey, enquanto, na avaliação das doses de $\mathrm{N}$ e do crescimento radicular após o pastejo, utilizou-se a análise de regressão. O nível de significância adotado foi de $10 \%$. Por meio das equações de regressão, foram calculadas as doses de nitrogênio que resultaram na densidade máxima de comprimento e de MS das raízes.

\section{Resultados e Discussão}

As interações doses de $\mathrm{N} \times$ profundidades de amostragem e ciclos de pastejo $\times$ profundidades de amostragem foram significativas para as densidades de comprimento e de MS das raízes no pré-pastejo. Para a variável crescimento de raízes, em densidade de comprimento, detectou-se interação significativa doses de nitrogênio $\times$ dias de amostragem das raízes após o pastejo. No entanto, para densidade de massa das raízes após o pastejo, houve somente efeito dos fatores principais, ou seja, das doses de nitrogênio e dos dias de amostragem das raízes após o pastejo.

Verificou-se efeito quadrático da adubação nitrogenada sobre a densidade de comprimento e de massa das raízes no pré-pastejo (Figura 1) e sobre o crescimento das raízes da gramínea (em densidade de comprimento e de massa) após o pastejo (Figuras 2 e 3). Na média das três profundidades e dos três ciclos de pastejo, as densidades de comprimento e de massa máximas estimadas no pré-pastejo foram obtidas com as doses 204 e $206 \mathrm{~kg} / \mathrm{ha}$.ano, respectivamente. $\mathrm{Na}$ média dos dias de crescimento após o pastejo, o crescimento máximo das raízes em densidades de comprimento foi obtido com a dose de $\mathrm{N}$ de $192 \mathrm{~kg} / \mathrm{ha}$ e, em densidade de massa, com a dose $197 \mathrm{~kg} / \mathrm{ha}$.

A deficiência de $\mathrm{N}$ prejudica o crescimento do sistema radicular (Whitehead, 1990). Muller et al. (2001) verificaram menor densidade de raízes em pastagem degradada de capim-colonião (963 raízes contadas em telas de $50 \times 50 \mathrm{~cm}$ ) em comparação a uma pastagem produtiva (1190 raízes). Neste experimento, as menores densidades de comprimento e de massa das raízes na ausência de $\mathrm{N}$, se comparadas às obtidas com aplicação de N, 150 kg/ha (Figuras 1, 2 e 3), também podem estar associadas aos resultados obtidos por Sarmento et al. (2005) no mesmo experimento, ou seja, à baixa quantidade de MS de lâminas no pós-pastejo e ao baixo IAF residual das plantas não adubadas (média de
$174 \mathrm{~kg} /$ ha.ciclo e 0,28 , respectivamente) em relação à dose $150 \mathrm{~kg} / \mathrm{ha}$ (média de $721 \mathrm{~kg} /$ ha.ciclo e 1,12 , respectivamente). Thornton \& Millard (1996) concluíram que a MS de raízes das espécies Festuca rubra L. e Lolium perene L. foi diretamente proporcional ao IAF residual da gramínea.

Os resultados obtidos neste trabalho confirmam os encontrados por Cunningham (1968) e Whitehead (1990). Esses autores verificaram que doses menores de N proporcionam maior volume de raízes, enquanto doses altas resultam em menor produção de raízes. Giacomini et al. (2005) também obtiveram maior crescimento radicular (em densidade de comprimento) no pós-pastejo na dose de $150 \mathrm{~kg} / \mathrm{ha}$

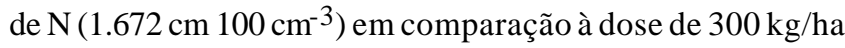

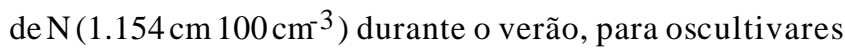
Aruana e Tanzânia de Panicum maximum Jacq. estabelecidos em Argissolo Amarelo.

$\mathrm{O}$ efeito da adubação nitrogenada no crescimento radicular é complexo e depende da fonte do nutriente, da
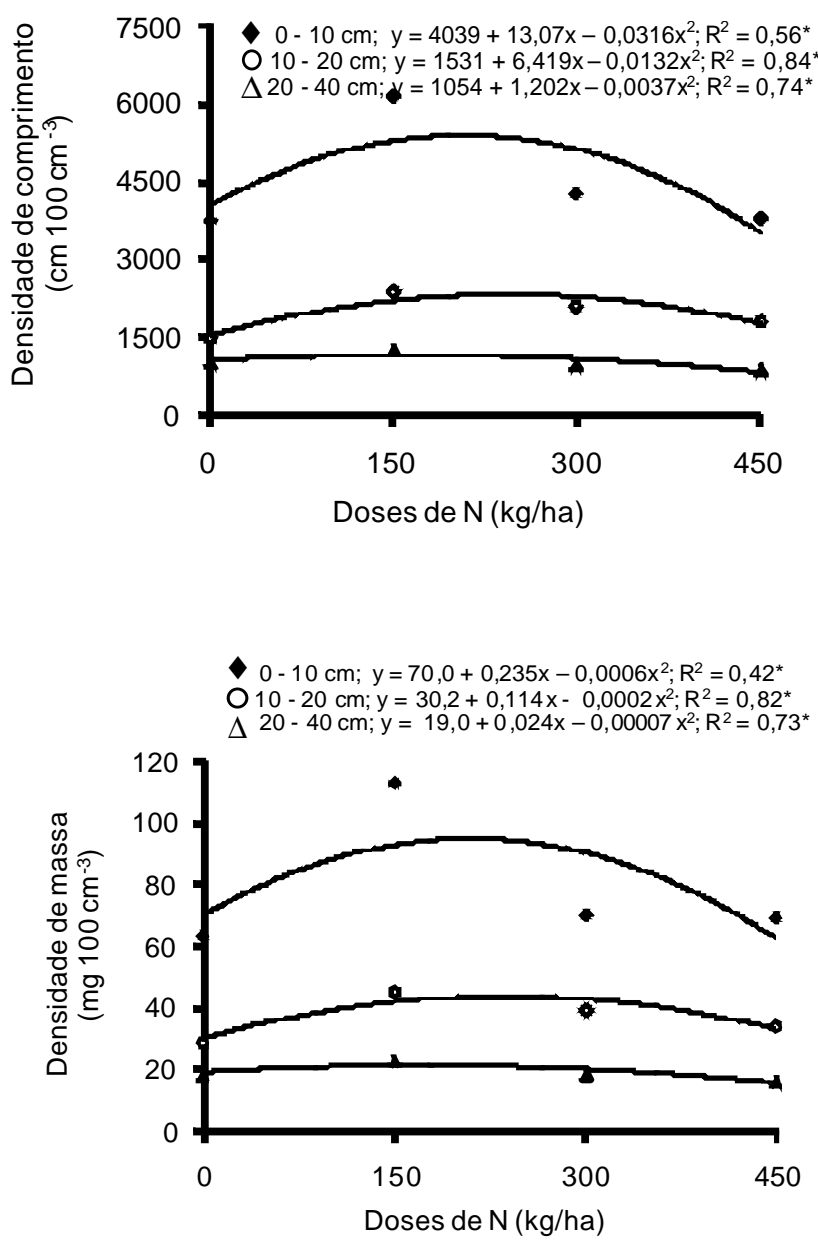

Figura 1 - Densidades de comprimento e de massa das raízes da espécie Panicum maximum Jacq. cv. IPR-86 Milêniono pré-pastejo, em cada profundidade do solo. 


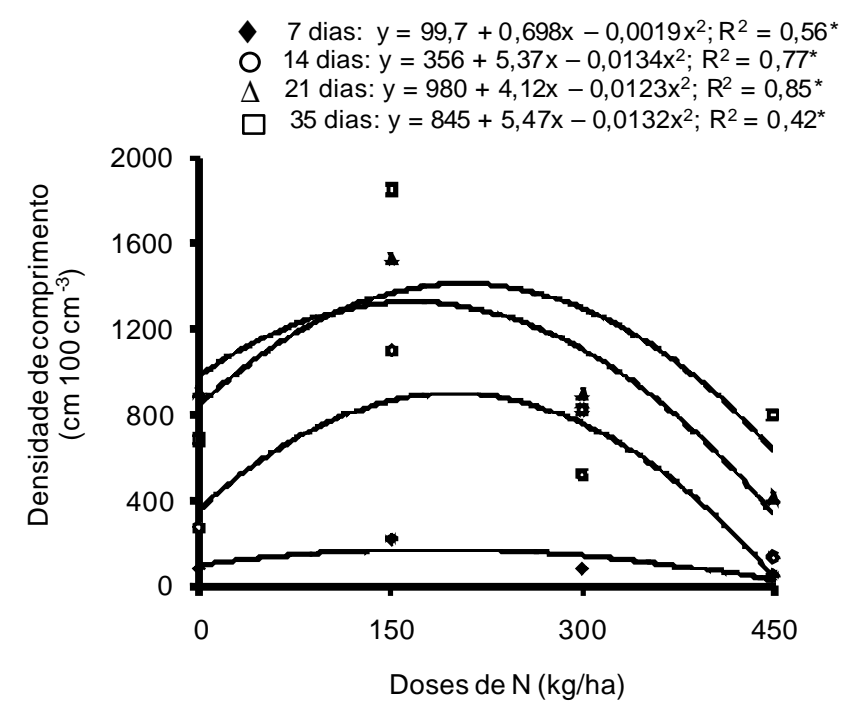

Figura 2 - Crescimento (em densidade de comprimento) de raízes da espécie Panicum maximum Jacq. cv. IPR-86 Milênio adubada com nitrogênio, em cada idade após o pastejo.

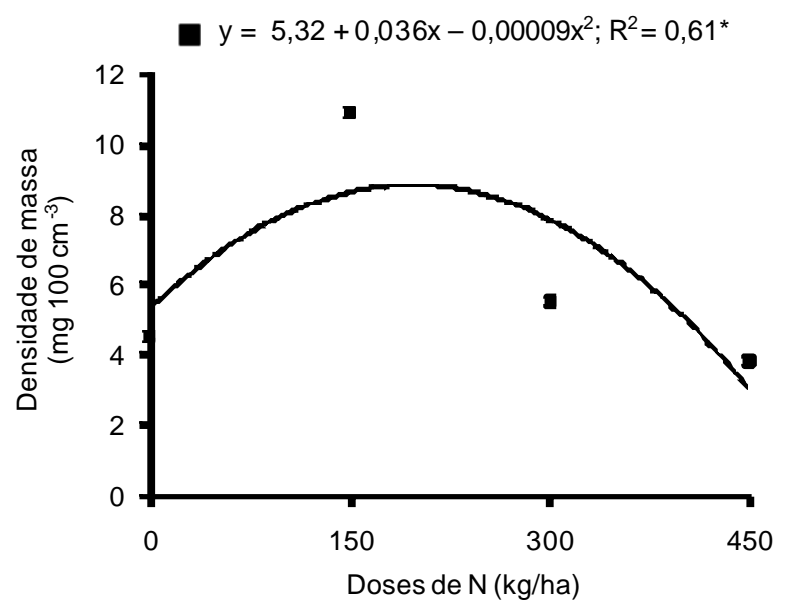

Figura 3 - Crescimento (em densidade de massa) de raízes de Panicum maximum Jacq. cv. IPR-86 Milênio no póspastejo (médias das idades após o pastejo).

quantidade e localização do adubo, do $\mathrm{pH}$, da umidade do solo, da atividade microbiológica (Gregory, 1994) e da espécie forrageira (Singh, 1999; Giacomini et al., 2005). Lavres Jr. \& Monteiro (2003), trabalhando em casa de vegetação utilizando sílica como substrato, estimaram que, para obtenção do comprimento total máximo das raízes do Panicum maximum Jacq. cv. Mombaça, é necessário o fornecimento de doses de $\mathrm{N}$ mais elevadas que as utilizadas no experimento, de 28; 112; 210; 336 e $462 \mathrm{mg} / \mathrm{L}$. Por outro lado, Giacomini et al. (2005) obtiveram menor densidade de comprimento de raízes dos capins Aruana e Tanzânia no pré-pastejo na dose de $\mathrm{N}$ de $150 \mathrm{~kg} / \mathrm{ha}$ ano

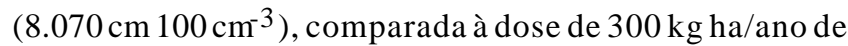

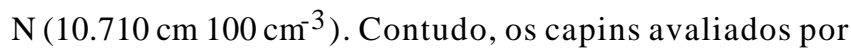

esses autores estavam no segundo ano após a implantação, enquanto neste experimento o pasto havia sido implantado há seis anos.

O aumento da produção de forragem, associado à adubação nitrogenada, resultou em aumento da lotação nas pastagens e em maior pisoteio animal, alterando os atributos físicos do solo (Sarmento et al., 2003), o que pode ter provocado decréscimo da densidade de comprimento e de massa das raízes do capim-milênio sob elevadas doses de N. Na área deste experimento, Sarmento et al. (2003) detectaram diminuição linear na porcentagem de macroporos do solo de 16,6 para 11,6\% com o aumento da dose de $\mathrm{N}$ de 0 para $450 \mathrm{~kg} / \mathrm{ha}$ na profundidade de $0-5 \mathrm{~cm}$. As raízes das plantas aproveitam os macroporos como caminhos preferenciais para seu crescimento. Além disso, como as raízes das plantas têm alta demanda por oxigênio, em virtude de sua alta taxa de respiração, com a diminuição da macroporosidade, ocorre redução da respiração do sistema radicular, prejudicando todas as suas funções (Marschner, 1995).

Outro fator que pode ter causado menores densidades de comprimento e de massa das raízes nas doses de 300 e $450 \mathrm{~kg} / \mathrm{ha}$ é a resistência do solo à penetração. Em avaliações realizadas no período seco, Sarmento et al. (2008) obtiveram valores de resistência do solo de 2,9; 4,5 e $4,9 \mathrm{MPa}$ (com umidade de 1,$9 ; 2,5$ e 2,3\%, respectivamente) na profundidade de $0-5 \mathrm{~cm}$ nas parcelas adubadas com $\mathrm{N}$ nas doses $150 ; 300 \mathrm{e} 450 \mathrm{~kg} / \mathrm{ha}$, respectivamente. Semmel et al. (1990) mencionaram que valores de resistência do solo à penetração superiores a 2,50 MPa restringem a produtividade das plantas forrageiras. Neste experimento, isso não deve ter interferido no crescimento da gramínea quando o solo apresentou umidade maior que $9,0 \%$, pois nessa condição não ocorreu efeito significativo das doses de $\mathrm{N}$ na resistência do solo à penetração e o valor médio da resistência foi de 2,11 MPa (Sarmento et al., 2008).

$\mathrm{Na}$ média dos três ciclos de pastejo (CP1, CP2 e CP4), a dose de $\mathrm{N}$ estimada para máxima densidade de comprimento de raízes no pré-pastejo foi de $204 \mathrm{~kg} / \mathrm{ha}$. Nas mesmas condições, foram necessários $320 \mathrm{~kg} / \mathrm{ha}$ de $\mathrm{N}$ para a máxima produção estimada de lâminas (Figura 4). De acordo com Marschner (1995) e Singh (1999), a parte aérea das plantas geralmente cresce mais que as raízes com a aplicação de $\mathrm{N}$, resultando em diminuição da relação massa seca das raízes:parte aérea. A diferença entre as doses para máxima produção estimada de raízes e de lâminas é grande e, embora os efeitos da adubação tenham que ser medidos isoladamente em cada parte da planta, na recomendação da dose de $\mathrm{N}$ deve ser considerada a planta inteira. Admitindo que a produção da parte aérea é a variável de importância mais 
imediata na pastagem, para atingir $90 \%$ da produção máxima de lâminas, nesse caso, é necessária dose de $\mathrm{N}$ de $292 \mathrm{~kg} / \mathrm{ha}$. Aproximando para $300 \mathrm{~kg} / \mathrm{ha}$, verifica-se decréscimo na densidade de comprimento das raízes de 3,3\% e, com essa dose, é possível obter uma combinação satisfatória para a resposta das duas variáveis (Figura 4).

O crescimento das raízes (em densidade de comprimento e de massa) durante a rebrotação do capim-milênio apresentou resposta quadrática às idades de crescimento após o pastejo (Figuras 5 e 6), exceto a densidade de comprimento das raízes na dose $450 \mathrm{~kg} / \mathrm{ha}$, que apresentou aumento linear com as idades de amostragens. O crescimento das raízes (em densidade de comprimento) foi máximo aos 27; 32 e 27 dias após o pastejo para as doses 0; 150 e $300 \mathrm{~kg} / \mathrm{ha}$, respectivamente. Contudo, a idade para obtenção da densidade máxima de massa seca das raízes menteve-se fora do intervalo avaliado.

Na primeira semana após o pastejo e nas duas últimas semanas do período de descanso, a taxa de crescimento das raízes em densidade de comprimento foi menor que nos outros momentos de amostragem $(15 ; 57 ; 62$ e $7 \mathrm{~cm}$ $100 \mathrm{~cm}^{-3} \mathrm{dia}^{-1}$ para as amostragens realizadas aos $7 ; 14$; 21 e 35 dias após o pastejo, respectivamente), provavelmente porque no período posterior à desfolha, o perfilho em rebrota passa da condição de fonte para dreno, ocorrendo, portanto, transferência de carbono para a parte aérea e paralisação do crescimento radicular até que a área foliar formada seja suficiente para atender às necessidades do perfilho. Redução no crescimento radicular da planta logo após o pastejo foi também obtida por Giacomini et al. (2005).

A partir do momento de acentuada redução na massa radicular decorrente da desfolha, o aumento da mesma tende apresentar taxa proporcional ao crescimento da parte aérea (Dovrat et al., 1980). Contudo, a rapidez com que a parte aérea se refaz após a desfolha e o ritmo com que o crescimento de raízes ocorre dependem de uma série de mecanismos fisiológicos da planta forrageira (Corsi et al., 2001), como capacidade fotossintética do tecido foliar, reservas orgânicas da planta e absorção de nutrientes.

Houve decréscimo significativo nas densidades de comprimento e de massa das raízes no pré-pastejo com o aumento da profundidade do solo (Tabelas 2 e 3). Em geral, as raízes das gramíneas se concentram nos primeiros $20 \mathrm{~cm}$ de profundidade (Singh, 1999) e a variação na profundidade do sistema radicular das plantas está relacionada ao genótipo e à espécie (Gregory, 1994).
- massa seca de lâminas no pré-pastejo

- densidade de comprimento das raízes no pré -pastejo

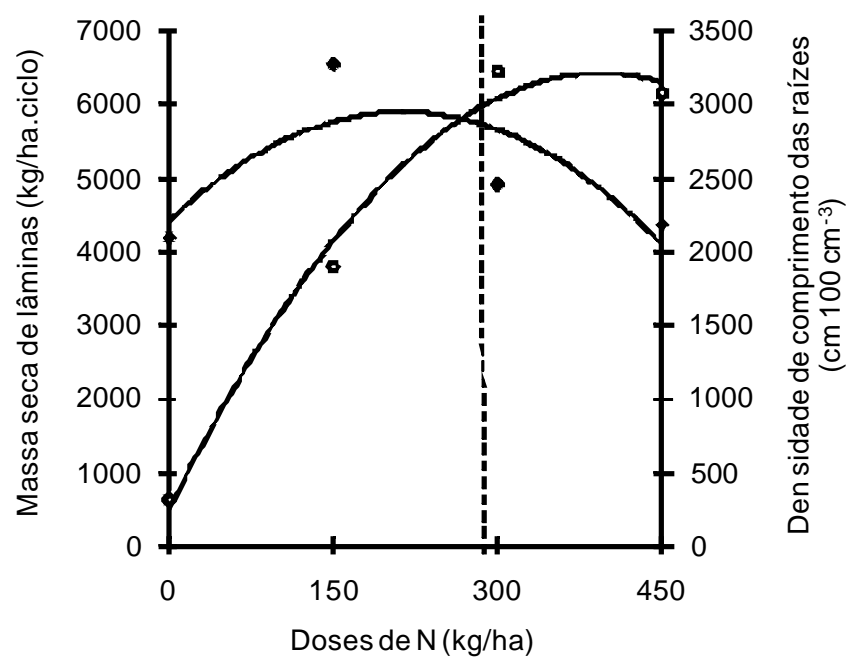

Figura 4 - Massa seca de lâminas e densidade de comprimento das raízes da espécie Panicum maximum Jacq. cv. IPR-86 Milênio no pré-pastejo em função da adubação nitrogenada (média dos ciclos de pastejo CP1, CP2 e CP4 e das profundidades do solo).

$0 \mathrm{~kg} \mathrm{~N} / \mathrm{ha} ; \mathrm{y}=-675+111 \mathrm{x}-2,05 \mathrm{x}^{2} ; \mathrm{R}^{2}=0,83^{*}$ $0150 \mathrm{~kg} \mathrm{~N} / \mathrm{ha} \mathrm{N} ; \mathrm{y}=-819+171 \mathrm{x}-2,70 \mathrm{x}^{2} ; \mathrm{R}^{2}=0,99^{\star}$ $\Delta 300 \mathrm{~kg} \mathrm{~N} / \mathrm{ha} ; \mathrm{y}=-653+117 \mathrm{x}-2,14 \mathrm{x}^{2} ; \mathrm{R}^{2}=0,99^{*}$ $\square 450 \mathrm{~kg} \mathrm{~N} / \mathrm{ha} ; \mathrm{y}=-191+28,1 \mathrm{x} ; \mathrm{R}^{2}=0,98^{*}$

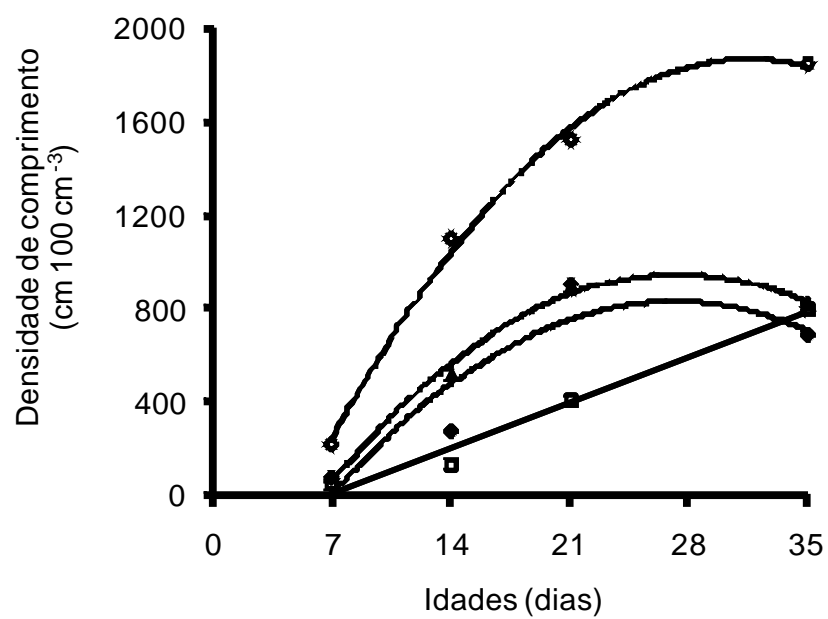

Figura 5 - Crescimento (em densidade de comprimento) das raízes da espécie Panicum maximum Jacq. cv. IPR86 Milênio após o pastejo em cada dose de nitrogênio. 


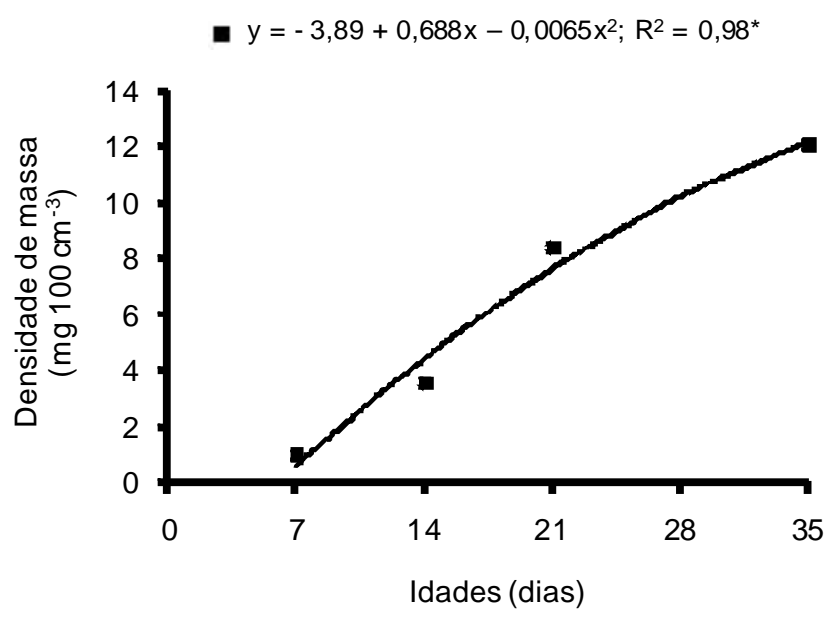

Figura 6 - Crescimento (em densidade de massa) das raízes da espécie Panicum maximum Jacq. cv. IPR-86 Milênio após o pastejo (média das doses de N).

A concentração das raízes na camada de $0-10 \mathrm{~cm}$ de profundidade (média de $60 \%$ ) pode ter sido influenciada pela concentração de nutrientes na superfície do solo (Tabela 1). Segundo Marschner (1995), a densidade de raízes de plantas aumenta em regiões com maior concentração de $\mathrm{N}$ e de $\mathrm{P}$. Em trabalho com Paspalum dilatatum Schum, Pennisetum glaucum L., Pennisetum purpureum Schum. e Brachiaria mutica Stapf., Singh (1999) obteve 65 a $86 \%$ do total de massa seca de raízes na profundidade de $0-20 \mathrm{~cm}$ e de 14 a $35 \%$ na profundidade de $20-60 \mathrm{~cm}$ quando não houve aplicação de nitrogênio. No entanto, com a aplicação de 50 a $150 \mathrm{~kg} / \mathrm{ha}$ na superfície do solo, houve aumento na proporção de raízes na camada superficial do solo (82 a 95\%) em comparação à camada mais profunda (5 a 18\%). Assim, o acúmulo de raízes nas porções mais superficiais do solo, em virtude da alta disponibilidade de nitrogênio, torna a planta mais vulnerável aos déficits hídricos. Neste experimento, 83;87; 86 e $86 \%$ do total de massa seca e $84,87,87$ e $87 \%$ do comprimento total de raízes do capim concentraram-se na camada de $0-20 \mathrm{~cm}$ para as doses $0,150,300$ e $450 \mathrm{~kg} / \mathrm{ha}$, respectivamente.

Quando a umidade do solo estava, em média, em 9\%, a maior resistência do solo à penetração (Sarmento et al., 2008) na camada de $10-20 \mathrm{~cm}$ de profundidade (2,51 MPa), comparada à camada de $0-10 \mathrm{~cm}(1,65 \mathrm{MPa})$, também pode ter contribuído para a concentração de raízes do capim na camada superficial do solo. Em experimento conduzido em vasos, Silva et al. (1992) obtiveram acúmulo de raízes dos capins gordura (Melinis minutiflora $\mathrm{P}$. de Beauv.) e colonião (Panicum maximum Jacq.) na camada do solo de 0-5 cm de profundidade. Nesse experimento, havia uma camada de solo compactada (densidade de $1,25 \mathrm{~kg} / \mathrm{dm}^{3}$ ) na profundidade de
5-10 cm, enquanto as camadas de 0-5 e 10-15 cm permaneceram com sua densidade inicial $\left(0,85 \mathrm{~kg} / \mathrm{dm}^{3}\right)$.

No CP4, avaliado no outono, verificaram-se menores densidades de comprimento e de massa das raízes no prépastejo nas profundidades de $10-20 \mathrm{~cm}$ e de $20-40 \mathrm{~cm}$, em comparação aos CP1 e CP2 (Tabela 3), o que indica redução

Tabela 2 - Densidades de comprimento e de massa seca das raízes de Panicum maximum Jacq. cv. IPR-86 Milênio no pré-pastejo em cada dose de nitrogênio (médias de três ciclos de pastejo)

\begin{tabular}{|c|c|c|c|c|c|}
\hline \multirow[t]{2}{*}{ Profundidade $(\mathrm{cm})$} & \multicolumn{4}{|c|}{ Dose de N (kg/ha) } & \multirow[t]{2}{*}{ Média } \\
\hline & 0 & 150 & 300 & 450 & \\
\hline \multicolumn{6}{|c|}{$\begin{array}{c}\text { Densidade de comprimento das raízes } \\
\text { no pré-pastejo }\left(\mathrm{cm} 100 \mathrm{~cm}^{-3}\right)\end{array}$} \\
\hline $0-10$ & $3.748 \mathrm{a}^{(1)}$ & $6.161 \mathrm{a}$ & $4.246 \mathrm{a}$ & $3.819 \mathrm{a}$ & 4.494 \\
\hline $10-20$ & $1.471 \mathrm{~b}$ & $2.377 b$ & $2.091 \mathrm{~b}$ & $1.811 \mathrm{~b}$ & 1.938 \\
\hline $20-40$ & $1.023 \mathrm{c}$ & $1.243 \mathrm{c}$ & $987 \mathrm{c}$ & $872 c$ & 1.031 \\
\hline $\begin{array}{l}\text { Média } \\
\mathrm{CV}=27 \%\end{array}$ & 2,081 & 3,260 & 2,441 & 2,167 & - \\
\hline
\end{tabular}

Densidade de massa das raízes no pré-pastejo $\left(\mathrm{mg} 100 \mathrm{~cm}^{-3}\right)$

\begin{tabular}{llcllc}
\hline $0-10$ & $63,2 \mathrm{a}$ & $113,0 \mathrm{a}$ & $69,9 \mathrm{a}$ & $69,4 \mathrm{a}$ & 79 \\
$10-20$ & $29,1 \mathrm{~b}$ & $45,4 \mathrm{~b}$ & $39,5 \mathrm{~b}$ & $34,3 \mathrm{~b}$ & 37 \\
$20-40$ & $18,5 \mathrm{c}$ & $22,6 \mathrm{c}$ & $18,4 \mathrm{c}$ & $16,4 \mathrm{c}$ & 19 \\
Média & 37,0 & 60,3 & 42,6 & 40,0 & - \\
$\mathrm{CV}=25 \%$ & & & & &
\end{tabular}

${ }^{1}$ Médias seguidas de mesma letra em cada coluna correspondente à mesma variável não diferem $(P>0,10)$ entre si pelo teste Tukey.

Tabela 3 - Densidades de comprimento e de massa seca das raízes de Panicum maximum Jacq. cv. IPR-86 Milênio no pré-pastejo adubado com quatro doses de nitrogênio

\begin{tabular}{lcccc}
\hline Profundidade $(\mathrm{cm})$ & \multicolumn{2}{c}{ Ciclos de pastejo $(\mathrm{CP})^{1}$} & \multirow{2}{*}{ Média } \\
\cline { 2 - 3 } & $\mathrm{CP} 1$ & $\mathrm{CP} 2$ & $\mathrm{CP} 4$ & \\
\hline \multicolumn{4}{c}{$\begin{array}{c}\text { Densidade de comprimento das } \\
\text { raízes }\left(\mathrm{cm} 100 \mathrm{~cm}^{-3}\right)\end{array}$} \\
\hline $0-10$ & $4.708 \mathrm{aA}^{2}$ & $4.855 \mathrm{aA}$ & $3.917 \mathrm{aA}$ & 4.493 \\
$10-20$ & $2.315 \mathrm{bA}$ & $1.906 \mathrm{bB}$ & $1.593 \mathrm{bC}$ & 1.938 \\
$20-40$ & $1.127 \mathrm{cA}$ & $1.084 \mathrm{cA}$ & $882 \mathrm{cB}$ & 1.031 \\
Média & 2.717 & 2.615 & 2.131 & \\
CV $=27 \%$ & \multicolumn{4}{c}{} \\
\hline
\end{tabular}

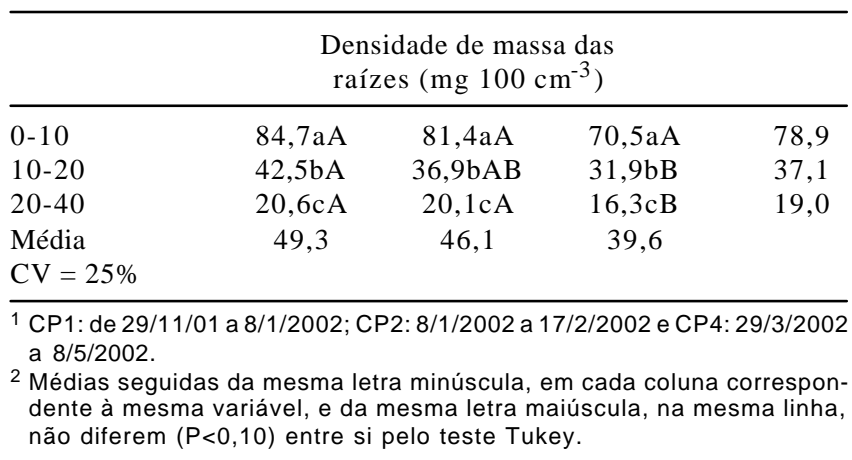


do crescimento do sistema radicular nesse período. Trabalhando com os capins Aruana e Tanzânia em Nova Odessa - SP, Giacomini et al. (2005) também obtiveram menores densidades de comprimento (53\%) e de massa (20\%) das raízes no pré-pastejo no outono, em relação ao verão.

As menores densidades de comprimento e de massa das raízes no pré-pastejo obtidas no outono podem também ser decorrentes da maior resistência do solo à penetração, em razão do decréscimo na precipitação pluvial. Segundo Marschner (1995), em mesma densidade, a resistência do solo à penetração aumenta com o decréscimo da umidade, dificultando o desenvolvimento das raízes.

O déficit hídrico afetou mais o crescimento da parte aérea da planta que o crescimento de raízes, resultando em típico aumento na proporção das raízes:parte aérea (Marschner, 1995). Neste mesmo experimento, Sarmento et al. (2005) detectaram que a quantidade de massa seca da parte aérea do capim diminuiu, em média, 30\% no quarto ciclo de pastejo, em comparação ao primeiro e ao segundo ciclos, em virtude do decréscimo da precipitação pluvial, enquanto a densidade de massa das raízes diminuiu em torno de $17 \%$ (Tabela 3).

\section{Conclusões}

A dose de nitrogênio estimada que proporciona densidade máxima das raízes da espécie Panicum maximum Jacq. cv. IPR-86 Milênio é $200 \mathrm{~kg} /$ ha e o crescimento máximo (em densidade de comprimento) é atingido em torno de 29 dias após o pastejo. Independentemente da dose de $\mathrm{N}$, aproximadamente $60 \%$ do sistema radicular do capim concentra-se na camada de $0-10 \mathrm{~cm}$ e cerca de $25 \%$ na camada de $10-20 \mathrm{~cm}$ de profundidade.

\section{Literatura Citada}

CORSI, M.; MARTHA JR., G.B.; PAGOTTO, D.S. Sistema radicular: dinâmica e resposta a regimes de desfolha. In: MATTOS, W.R.S. (Ed.) A produção animal na visão dos brasileiros. Piracicaba: Fundação de Estudos Agrários Luiz de Queiroz, 2001. p. 838-852.

CUNNINGHAM, R.K. Cation-anion relationships in crop nutrition. VI. The effects of part, age and species of plant and some soil characteristics. Journal of Agricultural Science, v.70, p.237244, 1968.

DONAGHY, D.J.; FULKERSON, W.J. The impact of defoliation frequency and nitrogen fertilizer application in spring on summer survival of perennial ryegrass under grazing in subtropical Australia. Grass and Forage Science, v.57, p.351-359, 2002.

DOVRAT, A.; DAYAN, E.; van KEULEN, H. Regrowth pontial of shoot and of rotos of Rodees grass (Chloris gayana) after defoliation. Netherland Journal of Agricultural Science, v.28, p.185-199, 1980.

GiACOMINI, A.A.; MATTOS, W.T.; MATTOS, H.B. et al. Crescimento de raízes dos capins Aruana e Tanzânia submetidos a duas doses de nitrogênio. Revista Brasileira de Zootecnia, v.34, p.1109-1120, 2005.

GREENWOOD, K.L.; McKENZIE, B.M. Grazing effects on soil physical properties and the consequences for pastures: a review. Australian Journal of Experimental Agriculture, v.41, p.1231-1250, 2001.

GREGORY, P.J. Root growth and In: BOOTE, K.J.; BENNETT, J.M.; SINCLAIR, T.R. et al. (Eds). Physiology and determination of crop yield. Madison: American Society of Agronomy, Crop Science Society, 1994. p.65-93.

LAVRES JR., J.; MONTEIRO, F.A. Perfilhamento, área foliar e sistema radicular do capim-Mombaça submetido a combinações de doses de nitrogênio e potássio. Revista Brasileira de Zootecnia, v.32, p.1068-1075, 2003.

MARSCHNER, H. Mineral nutrition of higher plants. 2.ed. London: Academic Press, 1995. 889p.

MULLER, M.M.L.; GUIMARÃES, M.F.; DESJARDINS, T. et al. Degradação de pastagens na Região Amazônica: propriedades físicas do solo e crescimento de raízes. Pesquisa Agropecuária Brasileira, v.36, p.1409-1418, 2001.

SARMENTO, P.; RODRIGUES, L.R.A.; LUGÃO, S.M.B. et al. Características físicas do solo em pastagem de Panicum maximum Jacq. (acesso BRA-006998) adubada com nitrogênio. In: REUNIÃO DA SOCIEDADE BRASILEIRA DE ZOOTECNIA, 36., 2003, Santa Maria. Anais... Santa Maria: Sociedade Brasileira de Zootecnia/Infovia, [2003]. (CD-ROM).

SARMENTO, P.; RODRIGUES, L.R.A.; CRUZ, M.C.P. et al. Atributos químicos e físicos de um Argissolo cultivado com Panicum maximum Jacq. cv. IPR-86 Milênio, sob lotação rotacionada, e adubado com nitrogênio. Revista Brasileira de Ciência do Solo, 2008 (no prelo).

SARMENTO, P.; RODRIGUES, L.R.A.; LUGÃO, S.M.B. et al. Respostas agronômicas e morfológicas de Panicum maximum Jacq. cv. IPR-86 Milênio, sob pastejo, à adubação nitrogenada. Boletim da Indústria Animal, p.333-346, v.62, 2005.

STATISTICAL ANALYSIS SYSTEM - SAS. Property software release 8. Cary: 1999. 956p.

SEMMEL, H.; HORN, R.; HELL, U. et al. The dynamics of soil aggregate formation and the effect on soil physical properties. Soil Technology, v.3, p.113-129, 1990.

SILVA, G.P.; NOVAIS, R.F.; NEVES, J.C.L. et al. Respostas de espécies de gramíneas forrageiras a camadas compactadas de solo. Revista Ceres, v.39, p.31-43, 1992.

SINGH, K.A. Effect of nitrogen levels on yield, root biomass distribution, nitrogen recovery by forage grasses and changes in soil properties of acid Inceptisol. Indian Journal of Agricultural Sciences, v.69, p.551-554, 1999.

TENNANT, D. A test of modified line intersect method of estimating root length. Journal of Ecology, v.63, p.995$1001,1975$.

THORNTON, B.; MILLARD, P. Effects of severity of defoliation on root functioning in grasses. Journal of Range Management, v.49, p.443-447, 1996.

Van RAIJ, B.; QUAGGIO, J.A.; CANTARELla, H. et al. Análise química do solo para fins de fertilidade. Campinas: Fundação Cargill, 1987. 170p.

VEEN; B.W.; BOONE, F.R. The influence of mechanical resistance and soil water on the growth of seminal roots of maize. Soil \& Tillage Research, v.16, p.219-226, 1990.

WHITEHEAD, D.C. Grassland nitrogen. Wallingford: CAB International, 1990. 397p. 